\title{
LITERATURA JUVENIL CONTEMPORÂNEA ENTRE A EMPATIA E O DESCONFORTO
}

Ana Crélia Dias (UFRJ)

Raquel Cristina de Souza e Souza (Colégio Pedro II/ UFRJ)

Resumo: A literatura juvenil gera críticas controversas em função de sua forte vinculação com a pedagogia. Embora sejam crescentes as publicações dirigidas ao público jovem, ainda é desconfortável para o mercado editorial e a escola a indicação de certas leituras. Essas reflexões são o objetivo desse texto, além da breve análise de dois títulos juvenis.

Palavras-chave: Narrativa de ficção, Público jovem, Escola, Mercado.

Abstract: The literature for the youth arises controversial criticism due to its straight connection to pedagogy. In spite of the increasing number of publications addressed to the youth, editorial market and school still feel uncomfortable in suggesting certain books. Thus, reflecting upon these questions and analyzing briefly two youth narratives are the aims of this article.

Keywords: Fictional narrative, Young audience, School, Market.

\section{QUESTÕES PRELIMINARES}

A literatura juvenil, à semelhança do que ocorre com qualquer literatura "adjetivada" - infantil, (de autoria) feminina, negra - está sempre às voltas com as implicações trazidas pelo rótulo que a define. Embora, cada vez mais, a universidade se abra crítica e teoricamente para acolher a produção voltada ao público jovem, não é sem controvérsia que esta adentra o sistema literário - e também o mercado. 
Os selos, coleções e séries direcionadas especialmente aos jovens, cujas obras correspondentes contam com projeto gráfico especialmente pensado para atrair essa faixa etária, assim como o espaço cativo e a posição de destaque que essa produção ocupa nas livrarias, feiras e bienais, não deixam dúvida de que ela é uma realidade editorial. A compra governamental de obras literárias destinadas às bibliotecas de todo o país é organizada de acordo com os níveis de ensino (Fundamental I, Fundamental II e Ensino Médio); os catálogos das editoras também são organizados geralmente por níveis de ensino e/ ou temas transversais. Muitos livros são acompanhados de fichas de leitura. Nos sites das editoras, na internet, há espaços reservados para professores, inclusive com dossiês pedagógicos, sequências didáticas e toda sorte de orientação sobre como utilizar o livro em sala de aula. Essa presença irrestrita, dirigida ao mediador especializado, demonstra que a literatura juvenil também é uma realidade institucional.

Sua realidade propriamente literária, no entanto, é constantemente colocada em questão. Isso acontece, em primeiro lugar, devido à sua origem "espúria", do ponto de vista dos processos de legitimação artística: a literatura juvenil nasce sob a tutela da escola e do mercado, na década de 70, a partir dos desdobramentos 
de uma reforma educacional que aumentou os anos de escolaridade obrigatória como uma das medidas para superar a crise da leitura do alunado brasileiro. A expansão do mercado, visando a atender um número considerável de leitores potenciais formados na escola, significou a criação de condições materiais mais favoráveis à consolidação da indústria editorial - e não só no campo literário infantil e juvenil -, além de ter selado de vez o casamento sempre rentável entre a instituição escolar e o mercado.

Em segundo lugar, o fato de ser a literatura juvenil definida por seu destinatário é um fator que colabora para sua marginalização dentro do sistema literário na medida em que coloca em xeque a questão do não pragmatismo da criação artística. Este destinatário pré-determinado acaba por selecionar temas (como aqueles relacionados às ideias de mutação e conflito: relação com a família e com o outro em geral, descoberta do amor e da sexualidade, inserção na vida social, construção da identidade) e formas (como a narrativa em primeira pessoa - não raro aproveitando-se do gênero diário - e a presença de adolescentes como protagonistas), o que, além de contrariar o princípio da liberdade criadora, flerta com certo didatismo e responde à lógica capitalista de segmentação do mercado. No entanto, o que uma safra significativa de autores contemporâneos tem mostrado, 
década após década, é que todas as limitações aparentes tornam-se, no fim, desafios criativos que os instigam a um nível de experimentação estética cada vez mais consciente e que gera resultados de alta voltagem artística.

Em suma, é o fato de terem sido fatores de ordem extraliterária os responsáveis pela emergência da literatura juvenil que faz com que muitos autores, com livros publicados sob a rubrica de "literatura juvenil", se recusem a assumir - ou assumam de forma enviesada - que escrevem para um público específico ou que se limitam por determinados temas e formas. O discurso praticamente homogêneo dos escritores quanto à busca pela qualidade literária em suas obras independentemente do público pode ser visto como uma forma de resistência a todas as injunções externas que colaboram para a depreciação da literatura infantil e juvenil no sistema literário.

Um dos argumentos mais utilizados por estes escritores (e também por parte da crítica acadêmica) é o de que uma obra de qualidade, rotulada de infantil ou juvenil, pode, ainda assim, promover prazer estético no adulto e, por isso, o rótulo seria dispensável. O problema é que o contrário quase nunca é verdadeiro, e por razões que fingimos ignorar, porque não queremos ver a literatura infantil e juvenil relegada à sub ou paraliteratura. Quantos leitores juvenis 
podem se afastar da literatura de qualidade quando entram em contato com livros inadequados para sua idade? Há um descompasso evidente entre a experiência de vida do autor adulto que escreve e a criança ou jovem que lê, de modo que o conhecimento de mundo partilhado é restrito; além disso, o domínio da linguagem e as competências leitoras também não são homólogas. O escritor, quando escreve para crianças e jovens, não pode ignorar que seu leitor é alguém em formação, em vários níveis, e que por isso partilha apenas parcialmente das suas referências culturais, convenções literárias e usos linguísticos. Caso contrário, a obra está fadada ao fracasso, no sentido da recepção.

O que constrange os escritores de literatura infantil e juvenil é justamente o emaranhado de condições externas que parecem conduzir e pré-determinar sua escrita, fato que tende a desmerecer o produto de seu trabalho aos olhos da crítica literária. A maioria dos depoimentos dos escritores converge no sentido de não assumirem fazer literatura segmentada, ainda que o projeto gráfico da obra desminta ou, o que é mais interessante, que o projeto de escrita desminta, seja pelo "respeito ao leitor", de que fala Delbrassine (2006), quando analisa o tratamento estético dispensado a temas polêmicos nas narrativas juvenis contemporâneas francesas, seja pela linguagem, 
pela construção dos personagens - que, via de regra, são espelhos do leitor -, seja pelo universo temático retratado.

A postura dos autores, entretanto, é absolutamente compreensível. O que eles querem dizer, e com o qual concordamos plenamente, é que não há diferença entre o texto literário infantil ou juvenil e o adulto no que diz respeito ao rendimento literário. A qualidade estética não é o que define um ou outro sistema; o que os define são condições diferenciadas de produção, circulação e consumo, que estão baseadas na assunção de um destinatário específico. Podemos afirmar, portanto, que a literatura juvenil é um subsistema literário, que funciona de forma autônoma no interior do sistema literário geral, ainda que mantendo com este estreita relação de influências mútuas.

O fato de a literatura juvenil contar com mecanismos e instâncias de legitimação próprias prova sua realidade literária, a par de sua realidade editorial e institucional. Eventos acadêmicos, revistas especializadas, prêmios literários específicos dão mostras de que há uma preocupação constante em atestar a qualidade da produção literária para jovens em moldes muito próximos ao que ocorre no sistema literário geral. Consequentemente, no interior do sistema juvenil, reproduz-se a polarização entre a produção legitimada literariamente (de circulação restrita, que 
concorre pelo capital propriamente simbólico) e a produção da indústria cultural (de circulação ampla, que concorre pelo capital econômico). O campo artístico-literário, como argumenta Bourdieu (1996), se caracteriza como um campo de forças opostas em disputa:

O processo pelo qual as obras são levadas [a se tornarem autônomas] é o produto da luta entre aqueles que, em razão da posição dominante (temporalmente) que ocupam no campo (em virtude de seu capital específico), tendem à conservação, ou seja, à defesa da rotina e da rotinização, do banal e da banalização, em uma palavra, da ordem simbólica estabelecida, e aqueles que estão inclinados à ruptura herética, à crítica das formas estabelecidas, à subversão dos modelos em vigor, e ao retorno a pureza das origens. (BOURDIEU, 1996, p.234)

A experiência em sala de aula com jovens leitores confirma essa polarização. As obras de literatura juvenil de qualidade atestada por diferentes instâncias raramente frequentam a biblioteca pessoal dos jovens espontaneamente. Apesar dos discursos congratulatórios que acompanham o que de melhor se tem produzido no Brasil para os adolescentes, o percurso destes livros até o seu leitor modelo final (já que, antes do jovem, o texto passa pelo crivo de inúmeros outros leitores modelos 
adultos) é bastante acidentado. Em contrapartida, o que chega de forma rápida e eficiente às mãos ávidas desses leitores em formação são as obras produzidas no polo oposto, o da indústria cultural, e com uma característica importante: em sua maioria, são obras importadas, de sucesso comercial em escala global, que contam com uma infraestrutura de mídia e marketing sem precedentes.

Até aqui, talvez não haja nada de muito espantoso. Se o sistema juvenil reproduz a dinâmica do sistema adulto, é natural que os best-sellers invadam também as prateleiras juvenis. Mas é então que deparamos com um fenômeno novo, que já conta com nome e estudos específicos fora do Brasil: o crossover. Este diz respeito aos produtos culturais que transpassam as barreiras de faixa etária previamente definida, seja do campo adulto para o infantil e juvenil ou vice-versa, sendo que, na contemporaneidade, o que tem chamado atenção é justamente a apropriação, por parte dos adultos, dos produtos comercializados com a rubrica "juvenil". No caso da literatura, os estudiosos apontam a publicação de Harry Potter, no final da década de 90, como um marco desse tipo de crossover. Foi a partir de então que o mercado norte-americano e europeu passou a publicar a saga de J.K. Rowling simultaneamente com projetos gráficos, juvenil e adulto, como documentam Sandra Beckett (2009) 
e Rachel Falconer (2009), para atender aos diferentes públicos. Isso, claro, provocou uma discussão que extrapolou a academia e invadiu diversos meios de comunicação. Não só a qualidade literária esteve no centro do debate, como também a suposta infantilização (ou "teenagização") do público leitor - que, aliás, seria uma característica da pósmodernidade: a valorização da juventude como um ideal cultural e um sintoma social. (COUTINHO, 2005).

Aqui no Brasil, a publicação dupla de Harry Potter nunca aconteceu. Mas basta uma olhadela rápida na lista dos livros mais vendidos para fazermos uma constatação interessante: a maioria absoluta das obras que lá figuram são as que, fora do país, recebem deliberadamente o tratamento de young adult literature. Navegando na internet, percebemos nas lojas virtuais e nas discussões de profissionais do ramo, assim como nos prêmios concedidos em categorias específicas ("child" e "young"), que o mercado internacional assim etiquetou os livros que hoje mais vendem em escala global.

Por aqui, embora o tratamento gráfico dispensado a esses livros seja "jovial", "arrojado", sem marcas de sisudez ou seriedade, em nenhum momento eles se mostram ostensivamente direcionados ao público juvenil propriamente dito. Só recentemente algumas editoras têm 
adotado a expressão "jovem adulto" em seus catálogos, mas, de maneira geral, tem-se optado por apagar as marcas juvenis da divulgação dos livros. Dois deles são ilustrativos a esse respeito, pela presença por longo tempo em nossas listas de mais vendidos, que, salientemos, não fazem distinção entre obras juvenis ou adultas: $O$ menino do pijama listrado, do escritor irlandês John Boyne, e A menina que roubava livros, do escritor australiano Markus Zusak. Os dois foram lançados no mercado internacional tendo como alvo o público adolescente ou jovem adulto, embora tenham se tornado crossovers, mas aqui perderam essa marca de origem. Certamente, devemos nos indagar sobre o porquê.

O fato de, no Brasil, a intenção juvenil ter sido obliterada pode ter a ver com a percepção de que, na falta do rótulo, e com a divulgação feita sem selo, projeto gráfico ou divulgação específica para o público juvenil, se poderia atingir um grupo maior de leitores. Outra hipótese é a de que as editoras podem não reconhecer nessas obras as marcas formais e/ ou temáticas que elas entendem serem características definidoras da literatura juvenil, por dois motivos: ou porque os temas e formas são acessíveis a qualquer público (exigem competências de leitura pouco sofisticadas), ou porque o texto é considerado inadequado para o jovem (por conta, por exemplo, da temática). 
Se as razões da obliteração da indicação de público juvenil estão no âmbito de nossas suspeitas, o reconhecimento de que há interesse do mercado nesse filão de público não traz dúvida. O volume de traduções e o investimento em autores que transitam bem entre os mais jovens cresceram muito nos últimos anos. A realidade de que há leitores juvenis - ao contrário do que se vivia há alguns anos - mostra-se com a circulação corrente de sagas e best sellers, os quais atingiram altos índices de vendagem, desde o fenômeno Harry Potter, e inauguraram prática pouco comum em tempos anteriores: a busca espontânea pelo livro por parte desse público leitor. Ou seja, os livros passaram a circular livremente entre os adolescentes, que se mostraram ávidos leitores de determinado filão.

O interesse da instituição escolar pela leitura dos alunos, uma vez que os leitores se formam independentemente do tipo de atuação da escola, a discussão sobre essa formação e o papel que a instituição nela desempenha têm sido alvo de investidas por parte não só do mercado, mas também das pesquisas acadêmicas, que outrora se negavam a reconhecer formação que não passasse pelo viés do cânone clássico.

Reconhecendo a importância de formar leitores e tendo a literatura juvenil como um dos caminhos, Ceccantini e Pereira trazem em Narrativas juvenis: outros modos de ler 
o posicionamento de um grupo de pesquisa que se debruça sobre a literatura juvenil para fazer-Ihe outro tipo de crítica: encaminham-se para o reconhecimento de que os critérios para julgamento das obras precisam ser coerentes com valores e ideias com as quais estas dialoguem:

É certamente denominador comum entre os autores dos estudos [...] o empenho em atribuir sentidos a uma produção literária contemporânea que cobra novas respostas interpretativas, seja no caso de obras mais criativas, seja na das que têm apenas como triunfo a empatia que despertam nos jovens, mas que, em ambos os casos, dão contribuição de peso para a formação de leitores num país de tradição iletrada. (CECCANTINI e PEREIRA, 2008, p.8)

Parece-nos claro que os autores de literatura, assumindo ou não, lançam-se à tarefa de promover em seus textos estratégias de aproximação do público, e isso não é novidade em se tratando de escrever para público de faixa etária diferente de seu produtor. Alice Martha, em "Lobato, o caçador de leitores", texto contido no volume citado, aponta a partir de pesquisas a cartas escritas por Lobato, que o escritor procurou com afinco dialogar com o público de leitores de seu tempo, e buscou a identificação de personagens com a faixa etária dos leitores, além de tentar aproximação também da temática e do gênero preferido desse público, a aventura: 
As cartas de Monteiro Lobato a Godofredo Rangel, além de textos de outra natureza, como prefácios e entrevistas, apontam as preocupações do escritor tanto em relação à sua formação - leituras e dúvidas relacionadas ao fazer literário - quanto sobre o leitor de suas obras, notadamente a criança. Assim, se no campo das ideias, podemos atestar o questionamento frequente de Lobato no que se refere à formação do leitor, é possível perceber que, no momento da produção, tais questões transformamse em trilhas de acesso ao texto, ou seja, materializam-se em aspectos como linguagem, perspectiva, ambientação, entre outros que, atendendo às especificidades de seus destinatários, contribuem para a desejada interação entre leitor e texto. (CECCANTINI e PEREIRA, p.27-28)

Parece-nos adequado afirmar que os livros dirigidos ao público jovem procuram, de forma deliberada (caso daqueles que negociam com os excessos midiáticos) ou não, promover um consórcio entre a identificação com o leitor, o assentamento no gosto (principalmente no que concerne ao encaminhamento formal) e a construção de uma escrita que não se renda a um tratado manualesco e desencontrado do discurso jovem. 


\section{DUAS LEITURAS JUVENIS}

Assumir a complexidade da tarefa de aproximar-se desse público e de seus valores estético-ideológicos, promovendo uma inter-relação entre discurso e identidade, dialogando intertextualmente com a representação de seu tempo é a busca incessante desse escritor, amparado por um mercado que enxerga futuro em investir em um filão que já deu frutos rentáveis nas empreitadas assumidas.

Teresa Colomer, em A formação do leitor literário, admite também essa complexidade de produzir texto literário para público diferente do sujeito autor, em termos de faixa etária e todas as implicações decorrentes dela. Analisando obras literárias infantis e juvenis, a autora aponta algumas incidências temático-formais e, dentre elas, destacamos certo "enfoque nos conflitos psicológicos" (COLOMER, 2003, p.263). Analisa ainda que o debate sobre questões sociais, por exemplo, admitiu outra dimensão de tratamento, e o engajamento social deixa de ser combativo para assumir nuances de denúncia genérica, a partir de incômodos particulares, muito aprofundados pela introspecção.

Analisaremos aqui duas obras consideradas juvenis, embora apenas uma delas tenha sido endereçada com clareza a esse público, como veremos mais à frente. Trata- 
se de Luna Clara e Apolo Onze, de Adriana Falcão, e Nada, de Janne Teller.

Em Luna Clara e Apolo Onze, o início da narrativa parece montar um painel de quadros, cuja relação, ainda caótica, vai acontecer no decorrer da narrativa, de modo a formar uma teia de encontros. A rede de intrigas, as idas e vindas, o grande elenco de personagens, que se desdobra em múltiplas atuações, tudo isso traz ao texto um ritmo frenético com forte acento dramático. Em outras palavras, este texto de Adriana, de certa forma, propõe um retorno a uma construção que foge à fragmentação de muitos textos contemporâneos, porém, também não se encaixa no modelo de estrutura linear simples, comum ao universo da literatura infantil, uma vez que a estratégia de sobreposição de cenas e acontecimentos assemelha-se ao ritmo da linguagem da trama televisiva. É um texto simples, mas permeado de possibilidades semânticas, as quais, muito embora transitem no território da impossibilidade, visto que têm aval do fantástico, chegam à solução. As características folhetinescas da fabulação de tramas comparecem e dialogam com a função de roteirista da autora.

Por meio de uma arquitetura em que emergem figuras extremamente significativas, Adriana apresenta, em Luna Clara e Apolo Onze, seres que têm objetivos comuns: a busca 
da felicidade. Texto delicadamente romântico, a história da menina que busca o pai e do menino que tenta encontrar sentido para a vida, caminha no universo do realismo fantástico que, ludicamente, proporciona o entrecruzamento de mundos paralelos, os quais convergem em direção ao mesmo propósito: o da aproximação dos casais. Nesse sentido, Adriana parece recuperar a estrutura do enredo tradicional, agora, entretanto, com nova roupagem, ritmo mais acelerado e figuras que não se constroem no tecido da idealização nem se despem de marcas da existência.

O que impulsiona a viagem de Luna Clara é o mesmo motivo do deslocamento de Apolo Onze - ela conscientemente, e ele, apenas por curiosidade. Seja por coincidência, acaso ou sorte, o encontro dos dois adolescentes estrutura-se com todos os detalhes, materializa-se na força da palavra adequada ao momento, numa estratégia evitada há tempos pelo texto literário pós-romântico.

A doçura do amor, do encantamento, da felicidade não foge ao happy end tradicional, mas parece inaugurar um estilo em que seu romantismo, se não resvala para uma concepção ingênua, entretanto não consegue se desvencilhar do palatável folhetinesco. Portanto, apesar de poder ser apontada como uma obra em que há certa apropriação do 
clichê de final feliz - afinal a história-núcleo tem um Apolo Onze que caminha em direção a Luna Clara, não contrariando o argumento de enredo esperado, surpreende na forma como é desenvolvido o relato, composto de criatividade, cheio de reviravolta, de trama.

A narrativa tem dois núcleos de protagonistas: os jovens e os adultos. $\mathrm{O}$ casal adulto situa-se como em uma narrativamoldura, da qual se originará a história de Luna Clara e Apolo Onze. O texto caminha na tendência de promover a oscilação entre os enfoques, ora nos protagonistas adolescentes, ora nos adultos. $O$ grande elenco de personagens têm seus nomes e/ou traços identitários ligados a elementos advindos de um arquivo de leituras da cultura ocidental: Odisseia, Divina, Aventura, Doravante, Pilhério, Seu Erudito, Leuconíquio, dentre outros que formam a grande fila de povoantes desse universo e revelam em seus nomes ou características suas heranças ligadas à literatura universal.

Em relação à estrutura do texto, teatro, cinema, música, roteiro televisivo parecem interferir na forma, conferindo à escrita uma feição híbrida e muito próxima do universo adolescente de confluência formal. Intercalam-se na obra texto verbal e não verbal; gêneros diferentes e vozes que sopram suas existências a um narrador que tudo dirige, 
sem apelo à estrutura linear. O que poderia se apresentar como certo desconforto ao leitor adolescente, que tem mais apreço pelas construções lineares, constitui-se como desafio, uma vez que o texto aponta características de um jogo de tabuleiro, desafiando o leitor a avançar e sentir-se como alguém que interfere nos desdobramentos narrativos, num processo em que o humor parece conduzir as empreitadas de leitura.

Assim, arriscamos dizer que a boa recepção desta obra deve-se a certo caráter de proximidade de discurso com o público, uma vez que a estrutura de roteiro, primando pela clareza, pelas frases curtas, prende a atenção do leitor. Além disso, o fato de ser uma aventura, repleta de reviravoltas e tramas, também se constitui como um dos motivadores de gosto do público adolescente. Apesar de uma obra ainda não tão vasta, Adriana Falcão já conseguiu visibilidade como escritora, com simplicidade e sem pretensões, transitando em terrenos diferentes, fazendo conexões que a academia poderia julgar impraticáveis.

Em lugar diferente do tom ameno e bem humorado da obra anterior, está o texto Nada, de Janne Teller. O livro foi lançado em 2000 na Dinamarca e na ocasião a publicação teve crítica controversa, chegando a ser suspensa a 
distribuição. Interessante é notar que algumas capas anteriores fazem menção a certa aproximação com a faixa etária jovem: uma ilustração similar a um desenho infantil ou em um projeto bem colorido e atraente. No caso da edição brasileira, a capa parece querer não se comprometer com esse endereçamento, mas também não abre mão de promover o livro: indica que se trata de um romance e traz a fotografia de um casal abraçado, além de indicar que se trata de um campeão de vendagem. Mesmo na ficha catalográfica brasileira, não há menção ao destinatário.

A narrativa conta a história de um grupo de adolescentes que se sente atormentado pelo discurso fatalista de um colega que resolveu se isolar do mundo e viver sobre uma árvore. O grupo, ao empreender a tarefa de encontrar o significado das coisas para convencer o colega do seu equívoco, incursiona num universo em que não há limites para conter o desejo individual, ancorado na capacidade de avançar rumo a níveis inimagináveis de crueldade. O relato é feito sob o ponto de vista da adolescente Agnes, participante do grupo. Os espaços privilegiados são a escola, a rua (especialmente no ponto em que está a ameixeira sobre a qual está Pierre Anthon, menino que aciona o dispositivo do conflito) e a serralheria. Apesar de serem 
espaços de encontro do grupo, o conceito de coletividade se potencializa antes pela força física e toda capacidade de repressão gerada por ela do que pela reflexão.

O discurso fatalista de Pierre Anthon: "Tudo só começa para acabar. Você começa a morrer no instante em que nasce. E isso vale para tudo" (TELLER, 2013, p.9) encontra nas crianças eco indesejável, uma vez que a obrigação de "ser algo na vida" advém de uma aculturação social em conflito com o estado psicológico dos adolescentes. A descrição inicial, assumindo contornos naturalistas, parece corroborar com o estado de tensão instalado com a atitude de Pierre Anthon e revela que o incômodo com a fala do colega está na identificação com o vazio verbalizado por ele, contra o qual os colegas não conseguem argumento e, na falta destes, recorrem à força física, ao sacrifício do corpo. Ou seja, a ausência da conviç̧ão na necessidade de "ser algo na vida", absorvida culturalmente, mas não internalizada identitariame nte, aproxima os adolescentes do niilismo de Pierre Anthon.

A tradução minimalista do sentido trágico da existência feita por Anthon revela aos olhos dos meninos um espaço escolar pouco atraente, e a angústia se materializa na feiura enxergada na escola: “O edifício era tão cinza, feio e quadrado 
que eu mal conseguia respirar; e de repente, era como se a escola fosse a vida; a vida não deveria ter essa aparência, mas tinha." (TELLER, 2013, p.11). Ao mesmo tempo em que desconfortável e repressor, o ambiente escolar parece oferecer maior segurança do que a vida para além da porta aberta deixada por Anthon:

A porta sorriu. Foi a primeira vez que a vi fazer isso. Pierre Anthon deixou a porta entreaberta como um abismo sorridente que poderia me engolir se eu me permitisse segui-lo. Sorria a quem? A mim, a nós. Olhei ao redor. O silêncio incômodo me revelava que os outros também haviam sentido o mesmo.

Deveríamos ser algo na vida. (TELLER, 2013, p.7)

O que se sucede a esse episódio é a tentativa deliberada de conter Anthon. A epígrafe do terceiro capítulo ("Uma ameixeira tem muitos galhos./ Muitos galhos infinitos./ Galhos infinitos demais") revela que o lugar ocupado pelo adolescente não é único e simboliza o desejo de outros de segui-lo, de ocupar espaços adjacentes naquela aventura. Em estrutura gradativa, que se repetirá ao logo do romance, o relato apresenta um estado de elaboração de Agnes, que será precedido de ação, visto o indesejado desconforto que causa. O que se segue é um planejamento meticuloso, em que se instala uma espécie de leilão perverso, feito 
inicialmente com subtração aos adolescentes de objetos repletos de valor sentimental para chegar à mutilação do corpo e até ao assassinato final. Sem mediação de um narrador distanciado, sem espaço para a análise moralizante, o texto despeja a crueldade adolescente em doses nem sempre homeopáticas de violência.

No caso desse livro, é interessante pensar que o compromisso da literatura juvenil com a pedagogia acaba por causar insegurança no professor de tomar a atitude de adotar esse livro na escola, em institucionalizar essa leitura sem mediação segura. Teresa Colomer (2003) trata da polêmica gerada por esse tipo de desenlace e aponta três críticas recebidas por esse tipo de obra: a de que crianças e adolescentes podem assimilar os pontos negativos; a de que a aceitação psicológica, se quer chocar e mexer com aquilo que não deve ser alimentado como estatuto de violência, pode ser tão didática quanto o final feliz; e, por último, a de que há o risco de o leitor se desinteressar pela leitura, diante do vazio final. Seja como for, as três principais críticas revelam a relação ainda não bem resolvida entre literatura dirigida à infância e à adolescência e a instituição escolar.

Nas incertezas que permeiam essa relação, estão a escola e o professor, que, se por um lado reconhecem que seus alunos seriam capazes de ler distanciadamente um texto 
brusco como Nada, acabam por reconhecer também que todas as barreiras legais e pedagógicas que protegem a infância e a adolescência em sua condição humana podem entender a literatura como veículo de ensinamento e um livro assim como estímulo à violência. E nesse caso o riso frouxo e os conflitos amenos de Luna Clara e Apolo Onze cabem melhor nesse consórcio complexo. Resta pensar até que ponto esse filtro radical protege e, mais ainda, se nele se formam leitores capazes de distanciar-se diante da representação ficcional.

\section{REFERÊNCIAS:}

Beckett, Sandra (2009). Crossover fiction: global and historical perspectives. New York: Routledge.

Bourdieu, Pierre (1996). As regras da arte: Gênese e estrutura do campo literário. São Paulo: Companhia das letras.

Ceccantini, João Luís; Pereira, Rony F. (Org.) (2008). Narrativas juvenis: outros modos de ler. São Paulo: Ed. UNESP; Assis: ANEP.

Colomer, Teresa (2003). A formação do leitor literário. São Paulo: Global. Coutinho, Luciana Gageiro (2005). A adolescência na contemporaneidade: ideal cultural ou sintoma social. (Pulsional: Revista de psicanálise n. 18). São Paulo, Editora Escuta.

Delbrassine, Daniel (2006). Le roman pour adolescents aujourd'hui: écriture, thématiques et reception. Paris: Academie de Créteil.

Falcão, Adriana (2002). Luna Clara e Apolo Onze. São Paulo: Moderna.

Falconer, Rachel (2009). The crossover novel: comtemporary children's fiction and its adult readership. New York: Routledge.

Teller, Janne (2013). Nada. Rio de Janeiro: Record. 
Ana Crélia Dias é especialista em Literatura Infantil e Juvenil, mestre e doutora em Literatura Brasileira pela UFRJ. Coordena o Núcleo de Estudos Interdisciplinares em Literatura Infantil e Juvenil da UFRJ. É professora da UFRJ.

Raquel Cristina de Souza e Souza é especialista em Literatura Infantil e Juvenil, mestre e doutoranda em Literatura Brasileira pela UFRJ. Leciona Português e Literaturas no Colégio Pedro II e participa do Núcleo Interdisciplinar de Estudos em Literatura Infantil e Juvenil da UFRJ.

Recebido em 29 de dezembro de 2015. Aprovado em 27 de abril de 2015. 